- IT offers many potential benefits to dentists.

- Benefits arise not from the IT directly, but from new ways of working.

- Increased usage of IT must be matched by increased maturity in information management and information governance.

- The Dental Practice Information Maturity Model (DPIMM) offers a tool to help manage this process.

\title{
Modelling the way that dentists use information: an audit tool for capability and competency
}

\author{
A. Gillies ${ }^{1}$ and J. Howard ${ }^{2}$
}

\begin{abstract}
Information, and the use of computers to provide that information, is becoming an increasingly important part of all aspects of clinical practice including dentistry. In 2003, a survey of English dental practices found nearly a quarter of practices were not using computers at all. Dental practices, whether NHS or private, can use information technology to provide significant benefits to patients and practices alike. In this article, a model is described for the maturity of information usage in dental practices. The model uses an approach successfully deployed previously in a range of applications in healthcare and other domains. The approach audits current maturity of usage and staff competency to help develop improvement plans for dental practices. The article describes how the model has been made freely available to dental practices over the Internet.
\end{abstract}

\section{INTRODUCTION}

In 2003, a survey of English dental practices found that nearly a quarter were still not using computers at all. Of those not using computers, over half (56\%) stated that they did not believe they were currently necessary. Around one quarter cited staff reluctance (24\%), while slightly fewer said that the systems were too expensive (19\%). Only 45\% had Internet and email access at this time. ${ }^{1}$

In 2002, the document An information technology strategy for NHS dentistry in the 21st century ${ }^{2}$ promised NHS dentists that:

1.2 Delivering $21^{\text {st }}$ Century IT Support for the NHS outlines a vision for the future of information in the

\footnotetext{
"Professor of Information Management, ${ }^{2}$ Senior Lecturer, Health Informatics, Faculty of Health, University of Central Lancashire, Preston, PR1 2HE ${ }^{*}$ Correspondence to: Professor Alan Gillies Email:acgillies@uclan.ac.uk
}

\section{Refereed Paper}

Accepted 12 July 2007

DOI: $10.1038 /$ bdj.2007.997

${ }^{\circ}$ British Dental Journal 2007; 203: 529-533
NHS. The priorities and challenges for NHS dentistry fit within this NHS-wide strategic approach to IT

1.3 The overriding theme of Options for change (OfC) is the re-integration of dentistry within the NHS and for dental records to become more connected with mainstream NHS IT

1.4 OfC requires the development and application of a standard oral health assessment and clinical pathways for dentistry, which will need to be applied consistently across the NHS. These will all need the support of an integrated IT strategy

1.5 Electronic records including digitised radiographs will need to be transferable between dentists and other organisations

1.6 To achieve this vision, there will need to be a substantial investment in education, training and change management for dental practice.

The American Dental Association ${ }^{3}$ claims the following benefits for computerised dental practices:
- Dental office computer systems should be compatible with those of the hospitals and plans they conduct business with. Referral inquiries should be handled easily

- Vendors should be able to supply low-cost software solutions to physicians/dentists which support standards-based EDI. Costs associated with mailing, faxing, and telephoning may decrease

- Administrative tasks can be accomplished electronically. Dentists may have more time to devote to direct care

- Dentists should have a more complete data set of the patient they are treating, enabling better care. More efficient systems may give dentists more time to spend with patients and performing clinical work.

However, experience from other sectors of healthcare has demonstrated that benefits realisation is complex and benefits derive from changes in working practices rather than from the technology itself. ${ }^{4,5}$ 
The authors have developed a model based around two distinct approaches that are combined to model the use of information by dental practices.

\section{The maturity model approach}

The first approach is a maturity model to assess process maturity. In November 1986, the US Government asked the Software Engineering Institute (SEI) to provide the federal government with a method for assessing the capability of their software contractors. In September 1987, the SEI released a brief description of the process maturity framework and a maturity questionnaire. ${ }^{6}$ This model, known as the Capability Maturity Model (CMM) is defined as a five-level framework for how an organisation matures its software processes from ad hoc, chaotic processes to mature, disciplined software processes. ${ }^{7}$

Paulk et al. ${ }^{8,9}$ describe the levels as shown in Table 1. The SEI CMM is questionnaire-based. Each question is a 'yes/ no' audit item.

The second part of the authors' model is based upon competency modelling.

\section{Competency modelling}

In 1984 Benner $^{10}$ outlined an adaptation of an earlier model of skill acquisition by Dreyfus ${ }^{11}$ as applied to nursing. Her model suggests a number of stages on the way to becoming a skilled practitioner. Benner describes these levels as being based upon three aspects of overall performance. Firstly, the paradigms shift from abstract rules to life experiences as the basis for behaviour. Secondly, a change in perception of situations, from a collection of disparate equal parts to a complete entity in which some parts have more relevance or importance than others. Third is the move from 'detached observer' to 'involved performer'.

Within this framework there are five stages through which the student will pass on their way to becoming an expert, as shown in Table 2. The key to using this model effectively is that skilled performance is not simply a measure of outcome, or simplistic behaviour, but includes the way in which the individual processes information before acting and then in the way in which they act in order to achieve a desired outcome.

A fundamental problem with the Benner model is that, across the board, an individual's performance is not uniform

\begin{tabular}{l|l|l|l|}
\multicolumn{2}{l}{ Table 1} & Five levels of the SEI CMM \\
\hline Level & Designation & Description \\
\hline 1 & Initial & The organisation has undefined processes and controls. \\
\hline 2 & Repeatable & The organisation has standardised methods facilitating repeatable processes. \\
\hline 3 & Defined & The organisation monitors and improves its processes. \\
\hline 4 & Managed & The organisation possesses advanced controls, metrics and feedback. \\
\hline 5 & Optimising & The organisation uses metrics for optimisation purposes. \\
\hline
\end{tabular}

\section{Table 2 Six levels of the Performance Model}

\begin{tabular}{l|l|l}
\hline Level & Designation & Description \\
\hline 0 & $\begin{array}{l}\text { Unskilled } \\
\text { /Not Relevant }\end{array}$ & $\begin{array}{l}\text { The individual is unable to perform this skill even under instruction or the skill } \\
\text { is not required in this role. }\end{array}$ \\
\hline 2 & Novice & $\begin{array}{l}\text { The individual has little or no experience in this aspect. Able to perform only } \\
\text { under close instruction or guidance. }\end{array}$ \\
\hline 3 & $\begin{array}{l}\text { The individual has some experience in this aspect and is able to perform with } \\
\text { minimal day-to-day supervision but still requires regular instruction or guid- } \\
\text { ance as new situations arise. }\end{array}$ \\
\hline 4 & $\begin{array}{l}\text { The individual performs in this aspect regularly and is able to work effectively, } \\
\text { without supervision, on a day-to-day basis, but may need occasional instruc- } \\
\text { tion, guidance or support when confronted with unusual situations. }\end{array}$ \\
\hline 5 & $\begin{array}{l}\text { Pkicient } \\
\text { Expert }\end{array}$ & $\begin{array}{l}\text { with only managerial supervision. Is capable of demonstrating this aspect } \\
\text { to others. }\end{array}$ \\
\hline $\begin{array}{l}\text { Highly skilful in this aspect with several years experience. The individual has } \\
\text { an intuitive grasp of the aspect and requires no supervision other than clinical } \\
\text { governance. Acts as a mentor and innovator in this aspect. }\end{array}$
\end{tabular}

Table 3 Three strands of information activity

\begin{tabular}{l|l|l}
\hline Activity type & If emphasised at expense of others & If neglected compared to others \\
\hline $\begin{array}{l}\text { Information } \\
\text { Technology }\end{array}$ & $\begin{array}{l}\text { The benefits will not be realised from the } \\
\text { technology: at best, it will just be under- } \\
\text { used and a waste of money: at worst, } \\
\text { it may lead to chaos. }\end{array}$ & $\begin{array}{l}\text { The lack of appropriate technology can } \\
\text { become a major barrier to improvements } \\
\text { in practice and information quality. }\end{array}$ \\
\hline $\begin{array}{l}\text { Information } \\
\text { Governance }\end{array}$ & $\begin{array}{l}\text { Overzealous governance processes can } \\
\text { stifle innovation, and in extremis make } \\
\text { the information systems almost impos- } \\
\text { sible to use through too many barriers } \\
\text { placed in the way of users. }\end{array}$ & $\begin{array}{l}\text { Inadequate governance procedures } \\
\text { can lead to breaches in privacy, consent, } \\
\text { inappropriate access. This may result in } \\
\text { litigation, bad publicity and professional } \\
\text { misconduct proceedings. }\end{array}$ \\
\hline $\begin{array}{l}\text { Information } \\
\text { Management }\end{array}$ & $\begin{array}{l}\text { There is little wrong with emphasising } \\
\text { information management except where } \\
\text { this leads to neglect of information } \\
\text { technology and governance processes. }\end{array}$ & $\begin{array}{l}\text { If you neglect information manage- } \\
\text { ment, you will lose many of the potential } \\
\text { benefits, waste money on technology } \\
\text { and time on establishing governance } \\
\text { processes. }\end{array}$ \\
\hline
\end{tabular}

in all aspects of their role. As the model is situational and experientially based, performance in disparate areas will necessarily be at different levels depending on theoretical knowledge and previous experience of the individual. In order to address this, the authors have used the skill acquisition model of performance to relate not to the whole individual, as is the case in Benner's work, but to selected facets of performance expertise against each competency item. Thus a clinician may be an expert in one competency item due to their level of experience and theoretical knowledge, whilst at the same time being a novice in a competency of which they have no experience or background knowledge.

Other limitations to this model are two fold. Firstly, the model of performance is context specific. Because the professional will use past experience as a 
filter when processing information, the accuracy of performance level measurement is limited to those situations where experience is relevant and related to the situation in which the worker finds him or herself. Thus, expert performance in a primary care setting will not necessarily produce the same level of performance if the individual moved to a secondary care situation. Secondly, the competency model could be regarded as reductionist. The authors argue that the approach deployed as part of this work goes some way to address this criticism. Because the competency items are not written as specific behavioural tasks that are either achieved or not, but rather as areas of clinical skill, the system retains the flexibility and adaptability to provide both clinicians and mangers with high quality data regarding training needs whilst addressing the complexity of developing clinical situations and supporting technologies.

In order to operationalise this model each individual is assessed against the matrix by selecting the appropriate row for his or her role. This provides a benchmark of the performance required in each competency item. Variance from this standard defines the presence, or absence, of development or training need. The authors have, with others, used this approach in a variety of settings to support the production of competency performance sets for general nursing, cancer nursing, public health, information management, mental healthcare and teenage sexual health. ${ }^{5,12,13}$ Through the use of a single matrix, all of these competency performance sets and all professional, and nonprofessional roles, can be managed on a unified system.

\section{The dental practice information maturity model}

The dental practice information maturity model (DPIMM) combines the two approaches to model the use of information by dental practitioners. We will start by defining three types of information activity:

- Information Technology: the technology associated with information: computers, wires, keyboards, etc. Contrary to popular opinion, whilst technology can really get in the way if it is not right, it cannot deliver benefits on its own
- Information Governance: the processes needed to ensure that you process information safely, securely and in accordance with best ethical and professional practice

- Information Management: the way you manage your information is crucial to gaining benefits from information. It is all about making sure that you have the right information in the right format at the right time and in the right place.

Each of these elements must be kept in balance with the others (Tables 3 and 4). Within our domain, the maturity levels are defined as follows.

In order to balance information technology, information governance and information maturity activities, the DPIMM model defines a distinct maturity for each strand. In an ideal world, the maturity level for each would be the same indicating balanced development. Problems will ensue if variations in maturity exceed one level between the strands.

The model itself has been developed through discussion with dental practice managers as part of an educational programme. The first strand to be considered is information technology, which is concerned with the technology, but also with the management processes required to manage the risks associated with the technology. For example, the audit items required to achieve level 1 maturity are: 1.1 Do you have a computer system in the practice?

1.2 Do all of the dentists in the practice have access to a computer system in the place where they deliver care?

1.3 Do you have a log of problems and errors with the systems?

1.4 Does the organisation use adequate virus protection software?

1.5 Do you back up all your data at least once a week?

1.6 Do you back up new information every day?

1.7 Is the system protected against an interruption in the power supply?

The model will define a maturity level, and define the tasks required to achieve the next level. Once the information technology maturity level is defined, next to be considered is information management maturity. If it emerges lower than the IT maturity then the practice is not getting the best from your technology. If it emerges higher, then the practice is doing well, but as improvements in information management are facilitated by technology so further improvements may be inhibited by limitations in technology.

Information management is key to achieving benefits. Benefits are derived not from the use of technology itself, but from the changes in working prac-

\section{Table 4 Maturity levels for the Dental Practice Information Maturity Model}

\begin{tabular}{|l|l}
\hline Maturity level & Characteristics of this level \\
\hline Initial & $\begin{array}{l}\text { Processes, procedures at this stage are ad hoc. The practice will have a computer } \\
\text { system, but it is used by the enthusiasts amongst the dentists, and for mandated } \\
\text { activities, or those with an immediate payback, eg billing; governance aspects are } \\
\text { covered by individual profesisonal codes of practice, and information management } \\
\text { is neglected. }\end{array}$ \\
\hline Improving & $\begin{array}{l}\text { The practice has started to define its processes. The dentists have started to use the } \\
\text { information system for clinical purposes. Basic policies are defined for consent and } \\
\text { confidentiality. Thought has been given to the information to be collected and used } \\
\text { within the practice. }\end{array}$ \\
\hline Systematic & $\begin{array}{l}\text { The practice has a full set of policies and processes. Information technology is } \\
\text { used throughouit the practice. Comprehensive governance policies are in place to } \\
\text { protect privacy. Basic indicators are used to monitor performance in respect of the } \\
\text { use of information. }\end{array}$ \\
\hline Payback & $\begin{array}{l}\text { The practice uses information across most of its activity. Informtaion is generated } \\
\text { routinely in support of audit and performance management. Activities for health } \\
\text { promotion are routinely supported by automated protocols, and data is input using } \\
\text { protocols to help standardise data entry. } \\
\text { Communications with the wider health community and other agencies are handle } \\
\text { electronically. Data is recorded to externally agreed standards. }\end{array}$ \\
\hline $\begin{array}{l}\text { Information is embedded within the culture of the practice. The practice operates } \\
\text { in a paperless fashion both internally and externally. Information is used to review } \\
\text { dental and business practices to underpin a culture of continuous improvement. }\end{array}$ \\
\hline Optimg
\end{tabular}




\begin{tabular}{|c|c|}
\hline Level & Description \\
\hline Level 0 & This does not form a part of the current or future role of the worker. \\
\hline Level 1- Foundation & $\begin{array}{l}\text { The practitioner would only practise whilst under the direct supervision of } \\
\text { others more proficient in this competency. (This level of attainment may apply } \\
\text { to the practitioner gaining experience and developing skills and knowledge in } \\
\text { the competency.) }\end{array}$ \\
\hline Level 2-Intermediate & $\begin{array}{l}\text { The practitioner can demonstrate acceptable performance in the competency } \\
\text { and has coped with enough real situations in the workplace to require less } \\
\text { supervision and guidance, but they are not expected to demonstrate full com- } \\
\text { petence or practice autonomously. }\end{array}$ \\
\hline Level 3-Proficient & $\begin{array}{l}\text { A practitioner who consistently applies the competency standard. The prac- } \\
\text { titioner demonstrates competence through the skills and ability to practice } \\
\text { safely and effectively without the need for direct supervision. (The Proficient } \\
\text { Practitioner may practice autonomously, and supervise others, within a } \\
\text { restricted range of competences. }\end{array}$ \\
\hline Level 4- Advanced & $\begin{array}{l}\text { The Advanced Practitioner is autonomous and reflexive, perceives situations as } \\
\text { wholes, delivers care safely and accurately and is aware of current best practice. } \\
\text { Advanced Practitioners understand a situation as a whole because they perceive } \\
\text { its meaning in terms of long-term goals. }\end{array}$ \\
\hline Level 5- Expert & $\begin{array}{l}\text { The Expert Practitioner is able to demonstrate a deeper understanding of the } \\
\text { situation and contributes to the development and dissemination of knowledge } \\
\text { through the teaching and development of others. The Expert Practitioner is likely } \\
\text { to have their own caseload and provide advice, guidance and leadership to other } \\
\text { professionals involved in the delivery or provision of health and social care. }\end{array}$ \\
\hline
\end{tabular}

Table 6 Required proficiency values are stored for each role at each maturity level

\begin{tabular}{l|l|l|l|l|l|l|l}
\hline \multirow{2}{*}{$\begin{array}{l}\text { Competency } \\
\text { Area }\end{array}$} & Role & \multicolumn{7}{|l}{ DPIMM Maturity level } \\
\cline { 2 - 9 } & Dentists & 0 & 1 & 2 & 3 & 4 & 5 \\
\hline Personal computers \& peripheral equipment & 0 & 2 & 2 & 3 & 3 & 3 \\
\hline Using mobile communications and computing & 0 & 0 & 0 & 1 & 2 & 3 \\
\hline File management & 0 & 2 & 2 & 3 & 3 & 3 \\
\hline Using a network & 0 & 1 & 2 & 3 & 3 & 3 \\
\hline Using word processing software & 0 & 2 & 2 & 3 & 3 & 3 \\
\hline Using spreadsheet software & 0 & 1 & 2 & 3 & 3 & 3 \\
\hline Using database software & 0 & 0 & 1 & 2 & 3 & 3 \\
\hline Using presentations software & 0 & 1 & 2 & 3 & 3 & 3 \\
\hline Using electronic mail & 0 & 2 & 2 & 3 & 3 & 3 \\
\hline Using Internet/intranet & 0 & 2 & 2 & 3 & 3 & 3 \\
\hline
\end{tabular}

tices facilitated by better information and information management. Examples of benefits include more reliable recalls, faster and more reliable identification of target patients or groups and more reliable identification of risks to patient safety, such as drug allergies or interactions. ${ }^{14}$

The final maturity audit is for information governance. As the use of information increases in both activity and complexity, so the governance issues increase. It is important to balance maturity in infor- information governance is organised into five maturity levels mirroring the levels of the other streams.

In professional liability terms, the fact that technology provides facilities for protecting data (access control, audits of user activity, backup facilities) means that failure to use these facilities leaves practices not using them properly in a worse position than those without them.

The maturity model is mirrored by the staff competency model, defined in terms of the approach pioneered by Benner ${ }^{10}$ and developed by Gillies and Howard. ${ }^{5}$ The model of proficiency is defined for each information competency area in terms of the scale shown in Table 5, and the level of proficiency defined for each staff role at each maturity level. A staff member whose own proficiency level matches or exceeds that required for their role is deemed to be proficient.

The model copes with the fact the practice use of information is dynamic. As the practice becomes more mature in their use of information, then the skill levels required by staff will increase, and proficiency levels required to achieve competence increase. The model is defined for each strand of information-based activity and for four staff roles: dentists, nurses, manager, and admin staff. An example is shown in Table 6, showing proficiency levels for dentists in IT in a practice with level 1 information maturity.

The model is encapsulated within webbased tools which are available in the public domain..$^{14,15}$ The tool is embedded within a portal (http://www.it4dentists. com) designed to provide advice and guidance in improving practice information maturity.

\section{DISCUSSION}

Information technology has met with limited enthusiasm from the dental community with perceived high costs and insufficient benefits to justify the expenditure.

In order to achieve benefits to justify the costs of investing in IT, dentists need to have a planned approach to implementation. In order to maximise the return on investment in the technology, it is necessary to match this with improvements in information management. It is also necessary to ensure that governance practice matures at a similar pace to protect against breaches in data protection and confidentiality. 
Experience from other sectors has demonstrated that a maturity model plus staff proficiency model can facilitate change, maximise benefits and provide demonstrable evidence of these benefits. Use of a balanced approach around information technology, information management and information governance, together with matched staff competencies maximises the probability of achieving benefits.

1. John J H, Thomas D, Richards D. Questionnaire survey on the use of computerisation in dental practices across the Thames Valley region. Br Dent J 2003: 195: 585-590.

2. Department of Health. An information technology strategy for NHS dentistry in the 21st century. London: HMSO, 2002.
3. American Dental Association. Health Information Technology Issues, Common Questions and Answers. 2006. http://www.ada.org/prof/ resources/topics/healthtech_questions.pdf Accessed February 2007.

4. Gillies A C. Can computers improve the health of the nation? Health Informatics J 1998; 4: 147-153.

5. Gillies A C, Howard J. Managing change in process and people: combining a maturity model with a competency-based approach. TQM and Business Excellence 2003; 14: 797-805.

6. Humphrey W S. Characterising the software process: a maturity framework. 1987. Software Engineering Institute, CMU/SEI-87-TR-11, DTIC Number ADA182895.

7. Paulk M C, Curtis W, Chrissis M B, Weber C V. Capability Maturity Model for Software, version 1.1. Software Engineering Institute, CMU / SEl-93TR-24, DTIC Number ADA263403. 1993a.

8. Paulk M C, Weber CV, Garcia S M, Chrissis M, Bush M W. Key practices of the Capability Maturity Model, version 1.1 Software Engineering Institute, CMU /
SEI-93-TR-25, DTIC Number ADA263432. 1993b.

9. Paulk M C, Konrad M D, Garcia S M. CMM versus SPICE architectures. Software Process Newsletter, IEEE Technical Committee on Software Engineering. 1995.

10. Benner P. From novice to expert: excellence and power in clinical nursing practice. California: Addison Wesley, 1984.

11. Dreyfus S E, Dreyfus H L. A five-stage model of the mental activities involved in skill acquisition. Unpublished report supported by the Air Force Office of Scientific Research. USAF, University of California: Berkeley, 1980

12. Storey L, Howard J, Gillies A C. Competency in health care. Abingdon: Radcliffe, 2002.

13. Wakley G, Chambers R. Sexual health matters in primary care. Abingdon: Radcliffe, 2002.

14. Gillies A C. IT and information for dentists: a handbook. London: Lulu Press, 2007.

15. Gillies A C. The Dental Practice Information Management Maturity Model. 2007. Online tools available at http://www.it4dentists.com. Accessed June 2007. 